\title{
Parthenogenesis and Sex-Ratio Distorting Bacteria in Empoasca (Hemiptera: Cicadellidae) Leafhoppers
}

\author{
Dora Aguin-Pombo, ${ }^{1,4,5}$ Marilia C. P. A. Rodrigues, ${ }^{2}$ Betsie Voetdijk, ${ }^{3}$ and \\ Johannes A. J. Breeuwer ${ }^{3}$
}

${ }^{1}$ Faculty of Life Sciences, University of Madeira, Campus da Penteada, Funchal, Madeira, Portugal, ${ }^{2}$ Secretaria Regional do Ambiente e Alterações Climáticas, Direção de Serviços dos Recursos Hídricos e Litoral, Funchal, Madeira, Portugal, ${ }^{3}$ Institute for Biodiversity and Ecosystem Dynamics, University of Amsterdam, Science Park 904, Amsterdam, The Netherlands, ${ }^{4}$ Centro de Investigação em Biodiversidade e Recursos Genéticos (CIBIO), Vairão, Portugal, and ${ }^{5}$ Corresponding author, e-mail: aguin@staff.uma.pt

Subject Editor: Dana Nayduch

Received 16 January 2021; Editorial decision 16 May 2021

\begin{abstract}
Endosymbiotic bacteria can induce parthenogenesis in many haplo-diploid species, but little is known about their role in asexual reproduction in diplodiploids. Bacteria are essential for reproduction in the asexual lineages of springtails and booklice, and possibly some weevils, but whether they are the causative agent of parthenogenesis remains to be proven. This would require comparing unisexual forms and their closely related bisexual species, but such model species are very rare. Empoasca leafhoppers from the Madeira Archipelago provide an excellent case to test whether bacterial infections can cause parthenogenesis. Here we examined the diversity of the sex-distorting bacteria, Wolbachia, Cardinium, Rickettsia, and Arsenophonus, in three apomictic morphotypes (A, B, C) and three bisexual relatives of Empoasca. Wolbachia of group $B$ was present in all unisexual and bisexual species. Rickettsia were the only bacteria restricted to the three unisexual forms, suggesting an association between infection and asexual reproduction. In addition, we found Asaia for the third time in the Cicadellidae, although this may have little to do with the reproductive mode of its host. Adult females of morphotype $\mathrm{C}$ reared on plants watered with tetracycline solution did not result in the production of male offspring. To our knowledge, this is the first study to suggest a possible association between bacterial infection and parthenogenesis in apomictic XO/XX diplodiploid bisexual species based on a range of sex ratiodistorting bacteria.
\end{abstract}

Key words: asexual reproduction, apomictic, endosymbiont, Wolbachia, Rickettsia

Many arthropods harbor endosymbiotic bacteria that are maternally inherited. Some of these bacteria can manipulate the reproduction of their hosts to increase the proportion of infected females. They can skew sex ratios by inducing parthenogenesis in haplodiploid species, feminizing genetic males, killing males during embryogenesis, or causing cytoplasmic incompatibility between gametes (Stouthamer et al. 1999, Werren et al. 2008). Wolbachia Hertig 1936 (Rickettsiales: Anaplasmataceae) is the best-known example of manipulative bacteria of host reproduction in arthropods (Werren and Windsor 2000, Hilgenboecker et al. 2008, Werren et al. 2008). Other manipulative reproductive parasites include Cardinium Zchori-Fein et al. 2004 (Sphingobacteriales: Flexibacteraceae), Rickettsia da Rocha-Lima, 1916 (Rickettsiales: Rickettsiaceae), Arsenophonus Gherna et al. 1991 (Enterobacterales: Morganellaceae), and Spiroplasma Saglio et al.
1973 (Entomoplasmatales: Spiroplasmataceae) (Saglio et al. 1973, Gherna et al. 1991, Duron et al. 2008, Engelstädter and Hurst 2009, Zchori-Fein et al. 2004, Ma et al. 2014). Bacteria-induced parthenogenesis has only been demonstrated in haplodiploid species of the orders Hymenoptera, Thysanoptera, and some Acari (Weeks et al. 2001, Kageyama et al. 2012). In these species, unfertilized eggs become haploid males and fertilized eggs develop into diploid females. Infected females do not produce male offspring, but convert all haploid eggs into parthenogenetic females (Stouthamer and Kazmer 1994, van der Kooi et al. 2017). When the bacteria are killed with antibiotics or heat, the cured females produce haploid males again, and the haplodiploid cycle is restored (Stouthamer and Mak 2002, Li et al. 2014). The mechanism by which bacteria induce parthenogenesis is not fully understood, but is often due to modification of meiosis (Suomalainen et al. 1987, 
Adachi-Hagimori et al. 2008, Ma et al. 2015) and less commonly due to postmeiotic changes (Stouthamer 1997). In contrast to haplodiploid species, there is no conclusive case of endosymbiont-induced parthenogenesis in diplodiploid species (Huigens and Stouthamer 2003).

The relationship between bacteria and parthenogenesis in diplodiploid species has been studied in the automictic springtail, Folsomia candida Willem, 1902 (Collembola: Isotomidae), and the booklice, Liposcelis bostrichophyla Badonnel, 1931 (Psocoptera: Liposcelididae). In this springtail, Wolbachia are necessary for egg viability (Pike and Kingcombe 2009, Timmermans and Ellers 2009), whereas in the booklice, Rickettsia are necessary for egg production (Yusuf and Turner 2004, Perotti et al. 2006). Despite this strong correlation, further studies are needed to understand whether bacteria are the cause of parthenogenesis. Unlike automictics, there are no studies specifically addressing the role of bacteria in asexual reproduction in apomictic lineages (Son et al. 2008, Mazur et al. 2016, Elias-Costa et al. 2019). A growing body of data on triploid and apomictic tetraploid weevils shows a significant correlation between endosymbionts and the reproductive mode of their host (Son et al. 2008, Lachowska et al. 2010, Rodriguero et al. 2010, Chen et al. 2012). Studies on diplodiploid species have so far focused almost exclusively on the effects of Wolbachia (Son et al. 2008, Chen et al. 2012, Elias-Costa et al. 2019), but searches should include other manipulative bacterial species as well (Hurst et al. 1999, Hurst 2000, Koivisto and Braig 2003, Duron et al. 2008).

Here we examine sexual and apomictic asexual Empoasca Walsh, 1862 leafhopper species from the Madeira Archipelago for endosymbiotic bacteria. Parthenogenesis is rare within Hemiptera species of the suborder Auchenorrhyncha (Gokhman and Kuznetsova 2017). On the Madeira Archipelago, three unisexual morphotypes of Empoasca leafhoppers coexist with three bisexual, two species of Empoasca and the closely related Asymmetrasca decedens (Paoli, 1932) (Hemiptera: Cicadellidae) (Aguin-Pombo et al. 2006, AguinPombo and Freitas, 2020). Unisexual forms are known only in Madeira, whereas bisexual species are widespread in Africa, Europe, and Central and North America, with the exception of E. alsiosa Ribaut, 1933, which is native to Madeira Archipelago, Canary Islands, and the western Mediterranean (Nast 1972, 1987). The other two bisexual species, E. fabalis DeLong, 1930 and A. decedens, are probably introductions from America (Aguin-Pombo and Freitas 2020) and Mediterranean region, respectively (Freitas and AguinPombo 2005, Aguin-Pombo and Freitas 2008). Empoasca is a worldwide distributed genus with about 800 species; many of them are known to be pests of crops and, except in Madeira, only one putative case of parthenogenesis is known throughout their range (Akingbohungbe, 1983). The bisexual species in Madeira are diploid with $\mathrm{XO} / \mathrm{XX}$ sex determination system, whereas the unisexual females reproduce by apomictic parthenogeneses. These morphotypes are morphologically very similar (Aguin-Pombo and Freitas, 2006, 2020) and have different chromosome numbers, morphotype $A$ and $\mathrm{B}$ are triploids, and morphotype $\mathrm{C}$ is diploid (Aguin-Pombo et al. 2006, Kuznetsova and Aguin-Pombo 2015).

Previous studies have shown that endosymbiotic bacteria can manipulate reproduction in other leafhoppers and planthoppers. In the planthoppers Laodelphax striatellus (Fallen, 1826) and Sogatella furcifera (Horvath, 1899) (Hemiptera: Delphacidae), Wolbachia and Cardinium induce cytoplasmic incompatibility between infected and uninfected hosts (Noda 1984, Hoshizaki and Shimada 1995, Noda et al. 2001, Nakamura et al. 2012, Zhang et al. 2012, Bing et al. 2019). In leafhoppers of the genus Zyginidia Haupt, 1929 (Hemiptera: Cicadellidae), Wolbachia can skew sex ratio toward females by feminizing genetically determined males (Negri et al. 2006) and may be responsible for the production of intersex individuals in Eupteryx Curtis 1829 leafhoppers (Hemiptera: Cicadellidae) (Henke et al. 2013).

In this work, we screen unisexual lineages and diplodiploid bisexual species of Empoasca for a full range of endosymbiotic bacteria known to cause parthenogenesis (Duron et al. 2008). We examined the effect of tetracycline on the reproductive biology of morphotype $\mathrm{C}$ to determine whether occasional males occurring in nature (D.A.-P., personal observation) are due to incomplete transmission of the bacteria by infected females.

\section{Material and Methods}

Asymmetrasca decedens has been regarded either a species of the genus Empoasca (Nast, 1987) or another species of the closely related genus Asymmetrasca. For simplicity, we will refer to all bisexuals as Empoasca species. Between November 2002 and March 2006, Empoasca samples were collected from native populations on Madeira Island by sweeping the vegetation with a net. Specimens were identified using informative morphological characters such as forewing veins, body size, and head shape (Aguin-Pombo and Freitas 2020).

\section{Bacterial Diversity Screening}

Bacterial diversity in leafhoppers was determined in two ways: by PCR using bacteria-specific primer pairs or by sequencing cloned bacterial $16 \mathrm{~S}$ ribosomal PCR amplicons. Ten to 20 females of the bisexual species E. fabalis, E. alsiosa, and E. decedens and the unisexual morphotypes A, B, and C were collected on Madeira Island and stored in $96 \%$ ethanol. Prior to DNA extraction, individual leafhoppers were surface sterilized by rinsing once with $70 \%$ ethanol and then washed twice in sterile water. The abdomen was then dissected in $95 \%$ ethanol and ground in $5 \mu$ l proteinase $\mathrm{K}(20 \mathrm{mg} /$ $\mathrm{ml})$ and $100 \mu \mathrm{l} \mathrm{CTAB} \mathrm{buffer}(2 \%$ CTAB w/v in $100 \mathrm{mM}$ Tris-HCl (pH8), $20 \mathrm{mM} \mathrm{EDTA}$, and $1.42 \mathrm{M} \mathrm{NaCl}$ ). After vortexing, samples were incubated at $55^{\circ} \mathrm{C}$ for $1 \mathrm{~h}$. Next, $100 \mu \mathrm{l}$ chloroform:isoamyl alcohol (24:1) was added, and the contents were mixed gently for $2 \mathrm{~min}$. The tubes were centrifuged at $15,800 \mathrm{~g}$ for $10 \mathrm{~min}$. After centrifugation, $80 \mu \mathrm{l}$ of the supernatant was transferred to a clean tube and the DNA was precipitated by adding $200 \mu \mathrm{l}$ ice-cold $96 \%$ ethanol. The tubes were incubated at $20^{\circ} \mathrm{C}$ for at least $1 \mathrm{~h}$ before centrifugation at $15,800 \mathrm{~g}$ for $15 \mathrm{~min}$ at $4^{\circ} \mathrm{C}$. The supernatant was removed, and the DNA pellet was washed with $70 \%$ ethanol. The DNA was then air dried for at least $15 \mathrm{~min}$, eluted in $30 \mu \mathrm{l}$ sterile water, and stored at $20^{\circ} \mathrm{C}$. DNA quality was systematically tested by polymerase chain reaction (PCR) amplification of a conserved region of arthropod mitochondrial COI with universal primers (Ma et al. 2014), which are listed in Table 1.

\section{Bacteria-Specific Screening}

Screening for Wolbachia, Cardinium, Rickettsia, Arsenophonus, and Asaia Yamada et al. 2000 (Rhodospirillales: Acetobacteraceae) was performed using species-specific primer pairs (Table 1). Leafhoppers yielding amplicons of the expected size were scored as infected with this bacterium. Negative samples for species-specific primer pairs but yielding a product of the expected size of cytochrome COI were retested. If the second test was also negative, these samples were noted as not infected with that bacterial species.

Amplifications were performed in $25 \mu \mathrm{l}$ reaction mixtures containing $2.5 \mu \mathrm{l}$ DNA extraction volume, $2.5 \mu 1$ 10× PCR buffer, $5 \mu 1$ 


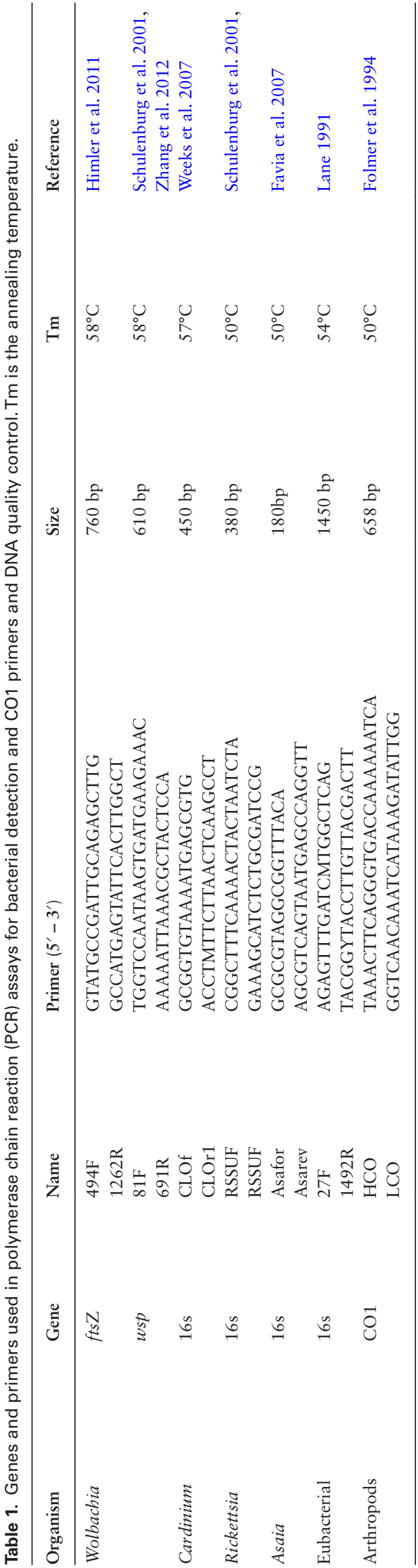

dNTPs mix, $0.2 \mu$ l of each primer $(20 \mathrm{uM}), 0.2-\mu 1$ Taq DNA polymerase $(5 \mu / \mu \mathrm{l})$, and ultrapure water. For $w s p$ and COI, the PCR mixture also contained $1.25 \mu \mathrm{lgCl}_{2}(25 \mathrm{mM})$. PCRs were performed under the following conditions: initial denaturation at $94^{\circ} \mathrm{C}$ for $2 \mathrm{~min}, 35$ cycles of denaturation $\left(94^{\circ} \mathrm{C}, 30 \mathrm{~s}\right)$, annealing $\left(50-55^{\circ} \mathrm{C}\right.$, depending on the primer, $30 \mathrm{~s})$, extension $\left(72^{\circ} \mathrm{C}, 1 \mathrm{~min}\right.$ to $1 \mathrm{~min}$ $30 \mathrm{~s}$ ), and a final extension at $72^{\circ} \mathrm{C}$ for $5 \mathrm{~min}$. PCR products were electrophoresed in a $1.5 \%$ agarose gel. When a PCR product was obtained, it was sequenced from two randomly selected individuals per infected species to ensure that the data set represented a true positive and not a PCR artifact or a related bacterium. Samples were purified using the NucleoSpin Extract 11 kit and sequenced using the forward primers and Big Dye 3.1 on an ABI PRISM 3730 automated DNA sequencer.

\section{Bacterial Diversity Identification}

We used general bacterial primers to amplify a 1,400 bp portion of bacterial $16 \mathrm{~S}$ rDNA from a pool of five leafhoppers per taxon to determine whether bacteria for which we had specific primer pairs were present in leafhoppers. The $16 \mathrm{~S}$ rDNA PCR mixture was identical to the mixture used for the bacteria-specific screen. The PCR conditions were as follows: initial denaturation at $94^{\circ} \mathrm{C}$ for $4 \mathrm{~min}$, followed by 35 cycles of 1 min denaturation at $94^{\circ} \mathrm{C}, 1 \mathrm{~min}$ annealing at $54^{\circ} \mathrm{C}$, and $1 \mathrm{~min}$ extension at $72^{\circ} \mathrm{C}$, concluded with a final extension at $72^{\circ} \mathrm{C}$ for $5 \mathrm{~min}$. The resulting PCR product was ligated into a plasmid vector, and this construct was used to transform E. coli. Ten clones per taxon were sequenced using standard sequencing protocols with M13 primers.

\section{Bacterial Species Identification}

After removal of PCR primers and vector sequences, bacterial sequences were compared with GenBank accessions using the Basic Local Alignment Search Tool (BLAST) to identify species. For general bacterial screening, we included $16 \mathrm{~S}$ rDNA sequences from representatives of the bacterial groups indicated in Moya et al. (2008). We also sequenced leafhopper Wolbachia fts $Z$ and wsp amplicons to determine to which Wolbachia supergroup they belonged. In all cases, relatedness between bacterial sequences was estimated using MEGA X (Kumar et al. 2018). Sequences were aligned using the default settings of CLUSTAL as implemented in MEGA. Relationships and bacterial identities of leafhoppers were inferred by constructing neighbor-joining phylograms with 500 bootstrap replicates based on unambiguously aligned sites using the substitution model proposed by ModelTest (Posada 2008). Sequences were deposited in GenBank (Accession numbers: 16S rRNA: MW970329-MW970343; wsp: MW926320-MW926324; and ftsZ: MW926325-MW926329).

\section{Tetracycline Treatments}

Antibiotics successfully remove Wolbachia from infected individuals of various insect orders ( $\mathrm{Li}$ et al. 2014). If Wolbachia is the causative agent of parthenogenesis, its removal restores normal sexual reproduction. Similarly, we studied the effects of Wolbachia on the reproductive biology of morphotype $\mathrm{C}$ to determine whether the occasional males in nature (D.A.-P., personal observation) may be due to incomplete transmission of the bacteria from infected females to their offspring. In similar studies on sap-feeding leafhoppers and planthoppers, the antibiotic is administered dissolved in water used to pot food plants (e.g., Zhang et al. 2020). The antibiotic is ingested while the insects suck the sap from the plant. We also exposed adults and nymphs of morphotype $\mathrm{C}$ to plants irrigated with a tetracycline 
solution. The progeny of $\mathrm{P}$ and F1 was examined for the presence of males to see whether sexual reproduction was restored.

Parental lineages were started with adult females collected in the field on Ricinus communis L., 1753 (Magnoliopsida: Euphorbiaceae) in Ribera Brava at a site $47 \mathrm{~m}$ above sea level. Three experimental cages were set up. In each cage, a bean plant about $25 \mathrm{~cm}$ high was placed with 20 adult females. Plants in two cages were watered daily with a tetracycline solution $(1 \mathrm{mg} / \mathrm{l})$. The food plants were watered only with this solution. The plant watered with water in the third cage served as a control. It cannot be excluded that some of these adult females produced males in the field. In order not to overlook any males, we examined all the offspring of these females. Thus, the effect of the antibiotic was studied in the F1 nymphs over a period of eight days. For this purpose, 80 nymphs less than $10 \mathrm{~d}$ old were distributed among four plastic cages, each containing one plant and 20 nymphs. The nymphs from adults reared on untreated plants served as control, whereas the nymphs of $\mathrm{P}$ females reared on plants exposed to tetracycline solutions were also treated with 1,3 , and $5 \mathrm{mg} / \mathrm{L}$ solution, respectively. Experiments were conducted at a photoperiod and temperature of $26 \pm 1.9^{\circ} \mathrm{C}(23.5-29)$ and humidity of $69.5 \pm 1.3 \%$ (67.1-71) according to the procedure described above.

\section{Results}

\section{Bacterial Diversity in Leafhoppers}

Ten clones with $16 \mathrm{~S}$ rDNA amplicons of each taxon were sequenced and compared against the GenBank $16 \mathrm{~S}$ rDNA database. Clades of the major bacteria known to be symbionts of insects, in particular Hemiptera, were obtained from GenBank. The final aligned data set contained 63 entries with a sequence length of 1,656 positions. The bacteria of Madeira leafhoppers can be broadly divided into four groups: Wolbachia, Rickettsia and Asaia (alpha-proteobacteria) and gammaproteobacteria (Fig. 1). The bacterium of E. alsiosa, which is close to Lactococcus lactis (Lactobacillales, Streptococcaceae), was considered a human contamination. The presence of Wolbachia and the absence of Cardinium and Arsenophonus in this general bacterial screening (Table 2) agreed with the specific PCRs for these species. Most interestingly, Rickettsia were present in all three unisexual morphotypes but were absent in the three sympatric bisexual species. The resulting neighbor-joining tree is shown in Fig. 2. Some internal branches are not well supported, and the phylogram does not necessarily represent the real phylogenetic relationships between clades. However, the phylogram does indicate the closest bacteria to the leafhopper symbionts.

The Wolbachia of Empoasca belong to strain B based on wsp and fts $Z$ sequences (Figs. 3 and 4). Strains A and B of Wolbachia are widely distributed among insects (Werren and Windsor 2000, Prakash and Puttaraju 2007) and are found in leafhoppers, including Empoasca (Delay, 2013), planthoppers (Noda et al. 2001), and some parthenogenetic weevils (Son et al. 2008).

Cardinium and Arsenophonus bacteria were not detected in any of our leafhopper samples using specific primer pairs nor with general bacterial $16 \mathrm{~S}$ rDNA primer pair. We did not detect either any of the known Hemipteran nutritional symbionts, such as Baumannia Moran et al. 2003 (Proteobacteria: Gammaproteobacteria), "Candidatus Sulcia" Moran et al. 2005 (Flavobacteriia: Flavobacteriales), Zinderia McCutcheon and Moran 2010 (Burkholderiales: Oxalobacteraceae), or Nasuia Noda et al. 2012 (Proteobacteria, Betaproteobacteria) (Fig. 1). However, we did find that all bisexual and unisexual Empoasca were infected with Asaia bacteria. In addition, we found some other gamma-proteobacteria in morphotype C and E. decedens that grouped with Serratia Bizio
1823 (Enterobacterales: Yersiniaceae) based on our phylogram analysis of the $16 \mathrm{~S}$ rRNA gene (Fig. 2). Similarly, closely related bacteria were also found in the brown planthopper, Nilaparvata lugens (Stal, 1854) (Hemiptera: Delphacidae), and bed bug, Cimex lecturalius Latreille, 1802 (Hemiptera: Cimicidae).

\section{Antibiotic Treatments}

Adult females of morphotype $\mathrm{C}$ reared on plants watered with tetracycline solution did not produce male offspring. Watering food plants with 1-mg tetracycline solution had no significant effect on adult survival (Fig. 5). All adult females from the control and from one of the two antibiotic trials survived, and in the third trial, $90 \%$ were still alive after $1 \mathrm{wk}$ of treatment. Females from the control and antibiotic trials did not differ in the number of offspring produced; control: 63 nymphs; trial 1: 58; trial 2: 96. First nymphs (F1) also appeared at similar times in the control and treatment trials; control: $7 \mathrm{~d}$; trials 1 and 2: $8 \mathrm{~d}$ each (Fig. 5). As with the adults, F1 nymphs from the control survived $(75 \%)$ but those reared on plants watered with tetracycline solution died regardless of antibiotic concentration. At 1,3 , and $5 \mathrm{mg} / \mathrm{l}$, nymph mortality reached $100 \%$ after 6,8 , and 8 d, respectively (Fig. 5).

\section{Discussion}

The symbionts of Empoasca species are largely unknown, but results from Madeira suggest that, like other leafhopper species (Takiya et al. 2006) and other Hemiptera (Thao et al. 2000, Baumann 2005, Downie and Gullan 2005, Iasur-Kruh et al. 2017, Gonella et al. 2019), Empoasca harbor a diverse bacterial community.

In our survey of the bacterial community of Empoasca, three groups of bacteria frequently showed up: Wolbachia, Rickettsia, and Asaia.

A first step to determine whether these bacteria may play a role in the induction of parthenogenesis is to look for associations between the mode of reproduction of the host and bacterial species. Wolbachia was not detected in individual specimens of E. alsiosa, the only native Empoasca species in Madeira, but a pooled control sample of five specimens tested positive, suggesting that the absence of this bacterium in E. alsiosa may be due to a lower bacterial load or very low prevalence. As in weevils, Wolbachia was more

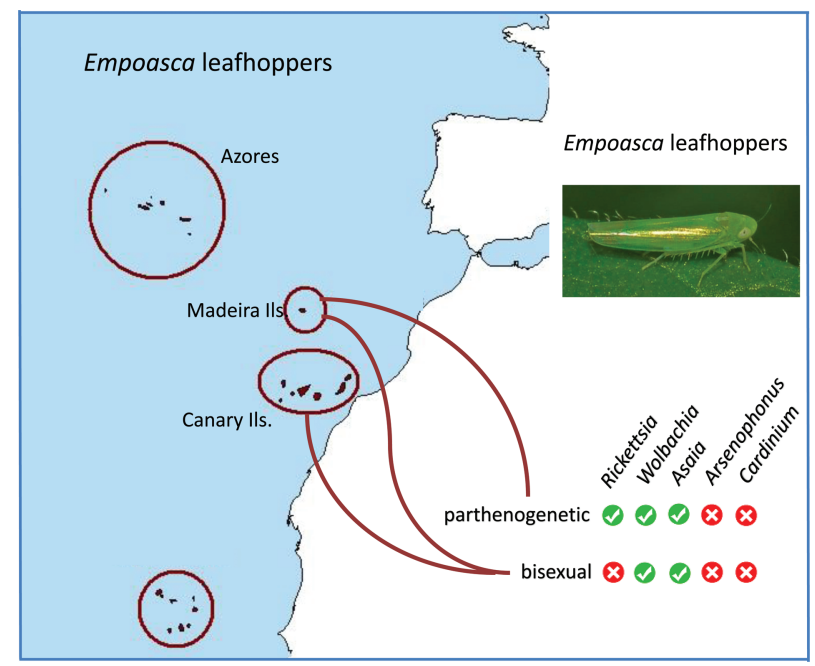

Fig. 1. Bacteria found in unisexual and bisexual leafhoppers Empoasca from Madeira, and distribution in Macaronesia, which includes the archipelagos of the Azores, Canary Islands, Cape Verde, and Madeira. 


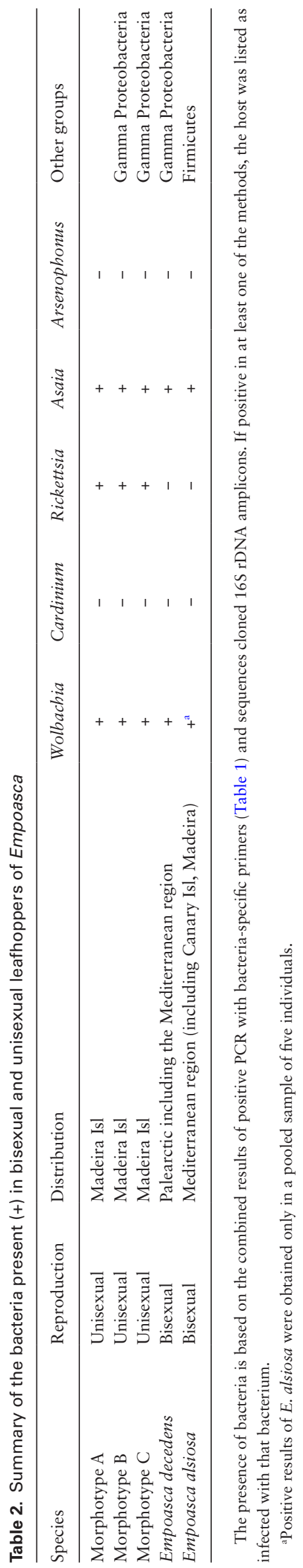

common in unisexual than in bisexual species (Lachowska et al. 2010, Rodriguero et al. 2010). However, its presence in both bisexual and unisexual Empoasca species suggests that Wolbachia is not directly linked to parthenogenesis.

Rickettsia were found in all three unisexual morphotypes but not in the bisexual species (Table 2, Fig. 1), indicating a possible link between infection and asexual reproduction. Rickettsia can be obligate endosymbionts (Perotti et al. 2006), reproductive parasites, or act simultaneously as nutritional mutualists and reproductive manipulators (Himler et al. 2011). As reproductive parasites, Rickettsia can cause male-killing (Lawson et al. 2001) and is invoked in parthenogenesis (Werren et al. 1994, Giorgini et al. 2010). For example, parthenogenetic populations of the booklice, Liposcelis bostrychophila, were also fixed for Rickettsia (Perotti et al. 2006, Perlman et al. 2015), whereas related bisexuals were not infected (Feng et al. 2018). When Rickettsia were removed, egg production stopped, suggesting that the bacteria may be involved in parthenogenesis of booklice (Yusuf and Turner 2004, Perotti et al. 2006). Rickettsia have been reported in Empoasca papaya Oman, 1937 (Davis et al. 1998), as well as other leafhoppers (Weinert et al. 2009, Noda et al. 2012, Ishii et al. 2013, Lian et al. 2016) and planthoppers (Gonella et al. 2011, Michalik et al. 2018), but the effects on host biology are still unknown.

Asaia bacteria were present in unisexual and bisexual Empoasca species. It is a newly discovered secondary symbiont of insects that belongs to the acetic acid bacteria family Acetobacteraceae. Asaia can be intracellular and can be both vertically and horizontally transmitted (Favia et al. 2007, Crotti et al. 2010, Gonella et al. 2018). This bacterium was recently found in the planthoppers, Nilaparvata lugens (Stal, 1854) and Sogatella furcifera, and in the leafhoppers, Scaphoideus titanus Ball, 1932 (Hemiptera: Cicadellidae) (Sacchi et al. 2008; Gonella et al. 2012, 2018) and Euscelidius variegatus (Kirschbaum, 1858) (Hemiptera: Cicadellidae) (Gonella et al. 2012). Although Asaia can have various functions in host biology (Roh et al. 2008) and fitness (Chouaia et al. 2012, Mitraka et al. 2013), it has not been shown to cause parthenogenesis. The fact that they are not specifically associated with unisexuals but were found in both unisexual and bisexual Empoasca species, makes it unlikely that they induce parthenogenesis in Empoasca.

We did not detect Cardinium and Arsenophonus in unisexual and bisexual species of Empoasca of Madeira. Although they have been reported in other leafhoppers (Bigliardi et al. 2006; Sacchi et al. 2008; Kobiałka et al. 2016, 2018a,b) and planthoppers (Gonella et al. 2011; Zhang et al. 2012, 2013; Qu et al. 2013; Bressan 2014; Li et al. 2018), so far in none of these cases they have been reported to be involved in reproductive manipulation of these hosts.

A second step to determine whether bacteria are involved in the reproduction mode of their host is to treat hosts with antibiotics to eliminate bacteria and observe changes in offspring number and sex ratio. If the bacteria of Empoasca cause parthenogenesis in diplodiploids, their elimination is expected to produce sterile females or females requiring sperm to fertilize eggs. However, the effects of these bacteria on the host are not all or nothing, as one would expect if parthenogenesis was induced by bacteria (Timmermans and Ellers, 2009). Antibiotic treatment of females of unisexual morphotype $\mathrm{C}$ did not provide a clear answer because the F1 offspring did not survive long enough to determine their sex. Mortality due to antibiotics could be due to several reasons. First, male development may simply no longer be possible due to the mutational erosion of genes involved in the process because they are not under selection. Second, antibiotics may kill bacteria that 


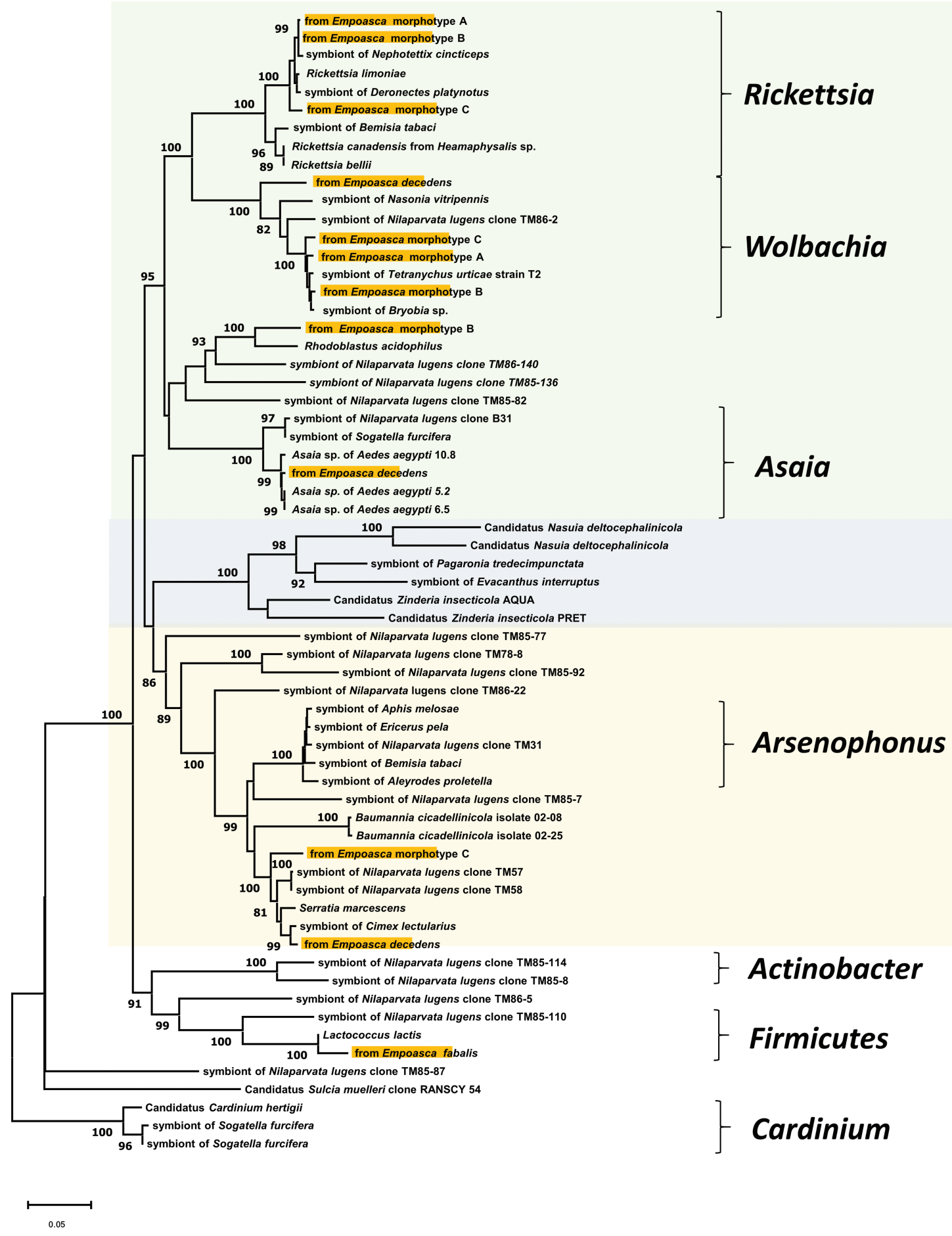

Fig. 2. Bacterial 16s phylogram constructed using the neighbor-joining method as implemented in MEGAX. Colored boxes overlay members of the alpha, beta, and gamma Proteobacteria. The analysis included 63 sequences. There were a total of 1656 positions in the final data set. All positions with gaps and missing data were eliminated. Tamura 3-parameter with a discrete Gamma distribution was used to model differences in evolutionary rate among sites (five categories $+\mathrm{G}$ parameter $=0.72$. The tree is drawn to scale, with branch lengths in the same units as the evolutionary distances used to infer the phylogram tree. The numbers on the branches indicate the percentage bootstrap support for the main branches (500 replicates; only bootstrap values of $80 \%$ or more are shown). Branch lengths are measured in the number of substitutions per site.

are vital to leafhopper development because they provide for example essential nutrients to their host. Studies on the planthopper Laodelphax striatellus showed that treatment with tetracycline affects the structure and composition of microbial communities. In some cases, such as Wolbachia, Bacteroides Castellani \&
Chalmers 1919 (Bacteroidales: Bacteroidaceae), and Abiotrophia Kawamura et al. 1995 (Lactobacillales: Aerococcaceae), almost $100 \%$ of the bacteria can be killed (Zhang et al. 2020), which can lead to a depletion of beneficial bacteria for the host. In the case of the unisexual springtail, Folsomia candida, eggs laid by cured 


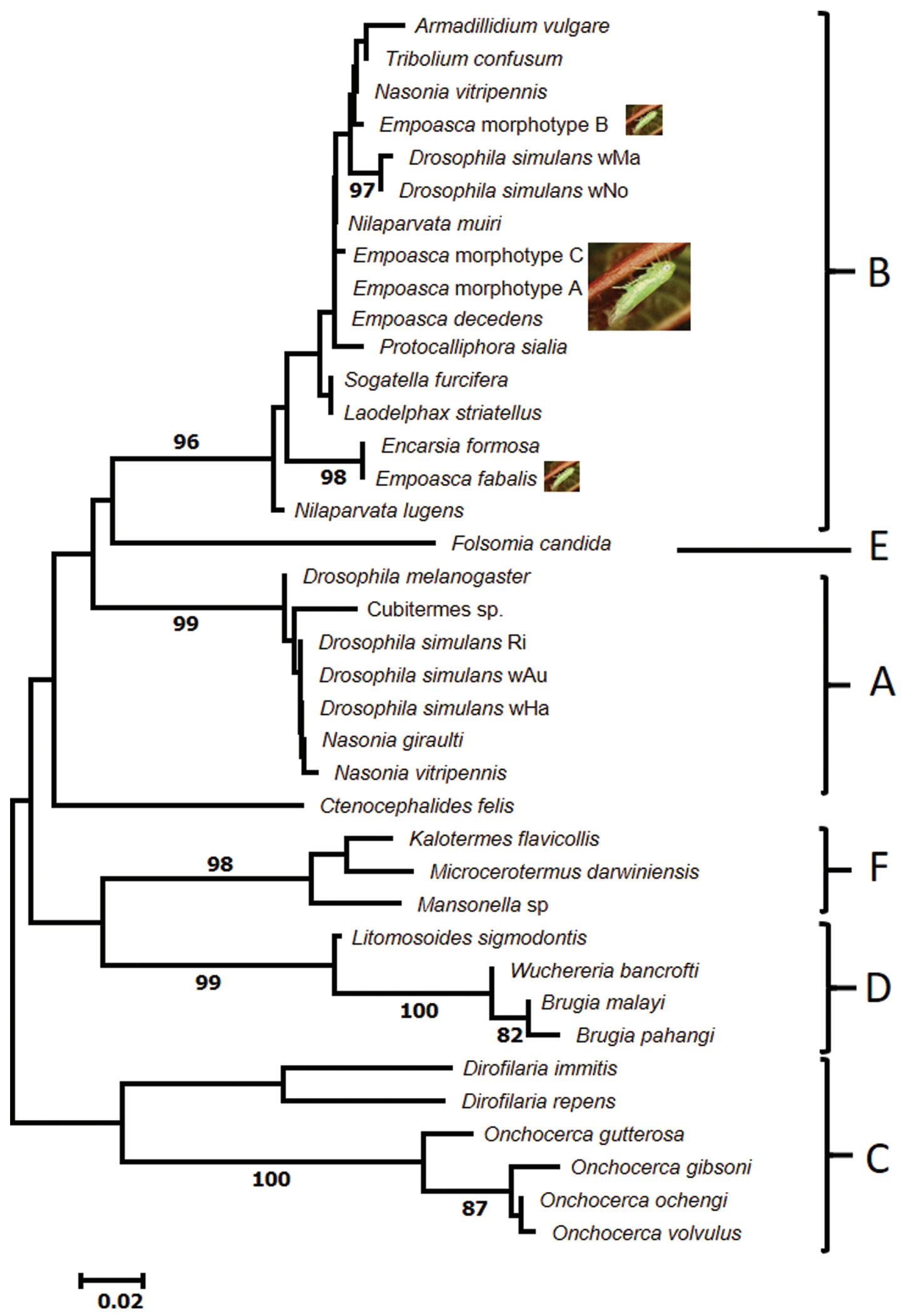

Fig. 3. Wolbachia ftsZ phylogram constructed using the neighbor-joining method implemented in MEGA $X$. The symbionts are indicated by the proper name of their host. Sequences from this study are shown in blue. Major Wolbachia supergroup lineages are reported (A-F). Unfortunately, no Wolbachia sequence information was obtained of $E$. alsiosa. The analysis included 38 nucleotide sequences. All positions with gaps and missing data were eliminated. A total of 377 positions were in the final dataset. Tamura 3-parameter with a discrete Gamma distribution was used to model differences in evolutionary rate among sites (five categories $+\mathrm{G}$ parameter $=0.2082$ ). The numbers on the branches indicate the percentage bootstrap support for the main branches (500 replicates; only bootstrap values of $80 \%$ or more are shown). The lengths of the branches are measured in the number of substitutions per site. 


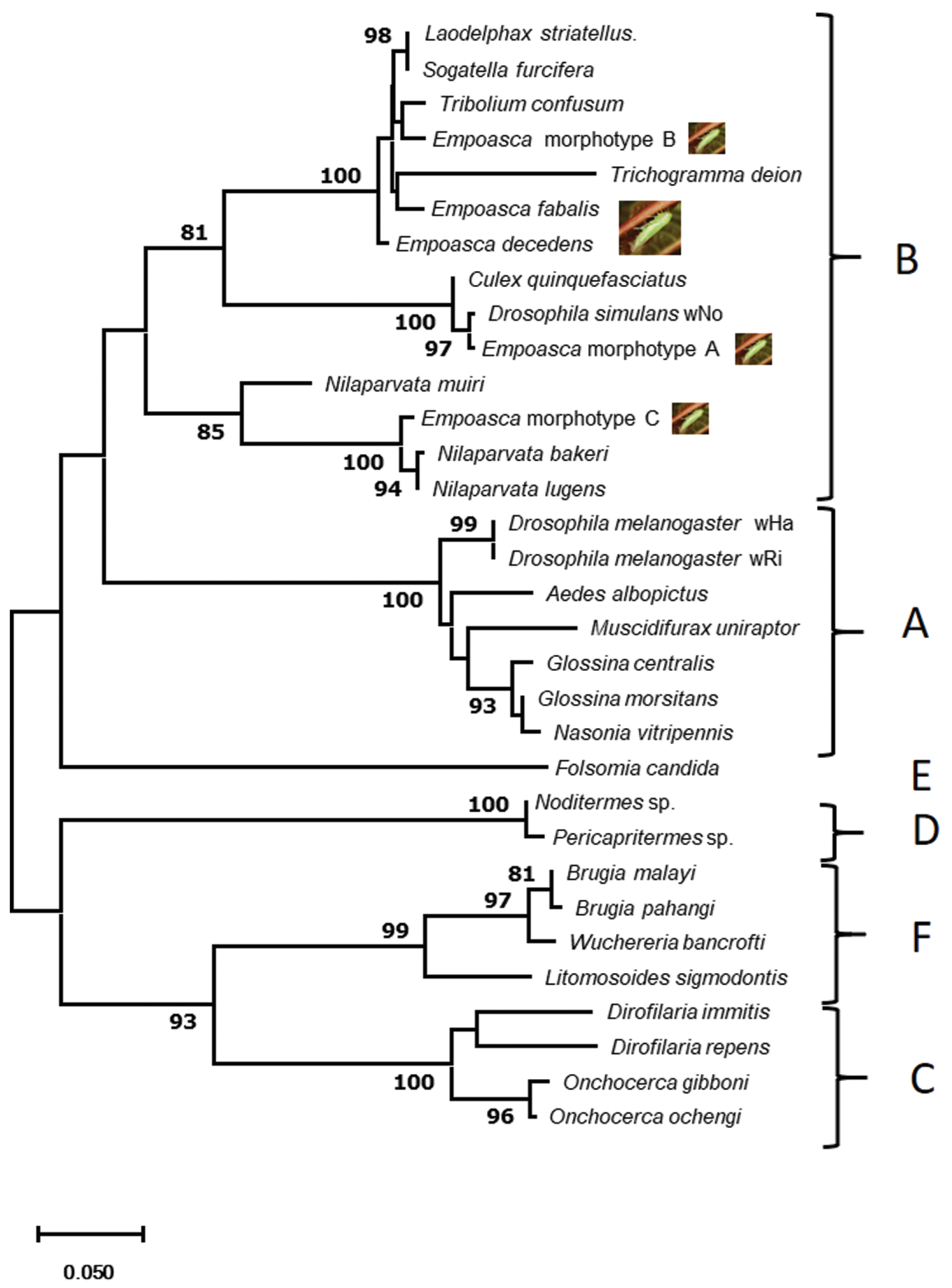

Fig. 4. Wolbachia wsp phylogram constructed using the neigbor-joining method implemented in MEGA X. Major Wolbachia supergroup lineages are indicated (A-F). Unfortunately, no sequence information of Wolbachia was obtained for E. alsiosa. Symbionts are indicated by the scientific name of their host. Tamura 3-parameter with a discrete Gamma distribution was used to model differences in evolutionary rate among sites (five categories $+\mathrm{G}$ parameter $=0.71$ ). The analysis included 32 sequences. All positions with gaps and missing data were eliminated. There were a total of 482 positions in the final data set. The numbers on the branches indicate the percentage bootstrap support for the main branches ( 500 replicates; only bootstrap values of $80 \%$ or more are shown). The length of the branches is measured in the number of substitutions per site.

females did not hatch or develop without Wolbachia, resulting in complete sterility (Frati et al. 2004, Pike and Kingcombe 2009). On the other hand, tetracycline itself inhibits protein synthesis (Dobson and Rattanadechakul, 2001), and thus can have direct lethal or sublethal effects on the host.
The fact that some unisexual Empoasca are triploid further complicates studies into the role of bacteria. If bacteria were responsible for the disappearance of males and the cause of parthenogenesis, administration of antibiotics to triploid XXX females would have to result in viable X0 males; however, this is unlikely. The high mortality 


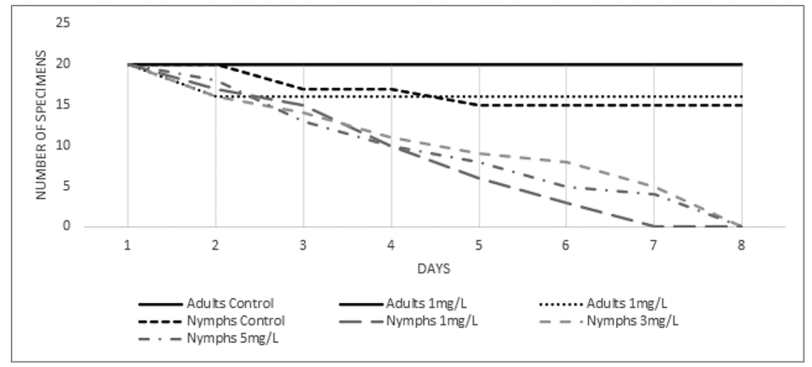

Fig. 5. Treatment with various concentrations of tetracycline. Lines are shown in black for adults and in grey for nymphs. In the adults, the control and the $1 \mathrm{mg} / \mathrm{l}$ treatment gave the same results, so the two lines overlap.

of nymphs suggests that production of males after antibiotic treatments is probably not possible. The fact that the unisexual forms are triploid seems to indicate a hybrid origin for morphotype A, but not for morphotypes B and C. One way to test this is to compare the phylogenies of nuclear and mitochondrial genes. Inconsistent phylogenies would indicate a hybrid origin of parthenogenesis. An additional limitation, at least for morphotypes $\mathrm{A}$ and $\mathrm{B}$, is that it is not easy to separate the effects of hybridization and polyploidy from those of endosymbionts to explain the origin of clonal variation; however for morphotype $\mathrm{C}$, which is diploid, this may be possible.

Surprisingly, we did not find bacteria in our 16S bacterial screen that are known nutrient endosymbionts of leafhoppers such as Sulcia and Baumannia (Michalik et al. 2018). It is unlikely that bisexual species and morphotypes of Empoasca leafhoppers do not have nutrient symbionts, as their diets and feeding habits are similar to those of other plant and leafhopper species, all of which rely on endosymbionts for essential nutrients not present in the host diet (Moran et al. 2008). Indeed, Sulcia muelleri Moran et al 2005 has been found in the potato leafhopper E. fabae (Delay, 2013). It is possible that eukaryotic symbionts remain undetected in our PCR, which uses primers designed to anneal to conserved regions of the bacterial 16S rRNA gene. However, our general $16 \mathrm{~S}$ rDNA primer set should pick Sulcia because both primer sequences match exactly with published 16s rDNA Sulcia sequences. Alternatively, Empoasca could use yeast or other unicellular eukaryotes instead of bacteria (Noda 1977, Sacchi et al. 2008, Michalik et al. 2009).

We postulate that Wolbachia, Rickettsia, or Asaia may have taken on this nutritional role. Asaia seems to be the most likely candidate, because of its omnipresence in all Empoasca species we screened. It has been reported in bacterial screens of other Hemipteran species such as the small brown planthopper Nilaparvata lugens and Laodelphax striatellus (Li et al. 2017; Zhang et al. 2019, 2020) and even as intracellular symbiont of the American grapevine leafhopper Scaphoideus titanus and the planthopper Sogatella furcifera (Gonella et al. 2012; Li et al. 2017, 2020; Zhang et al. 2019). Moreover, in Sogatella planthoppers, Li et al (2020) showed with antibiotic treatments that Asaia promoted larval development and adult weight, suggesting that it may be a nutritional symbiont. Also, in Anopheles Meigen 1818 mosquitoes (Diptera: Culicidae), is essential for larval development (Chouaia et al. 2012, Mitraka et al. 2013).

In leafhoppers and planthoppers, Wolbachia can be a facultative (Takiya et al. 2006, Bing et al. 2019) or an obligate symbiont. If we assume that tetracycline successfully removed Wolbachia from morphotype $\mathrm{C}$, the higher mortality of nymphs in the antibiotic experiments suggests that the bacterium may be necessary for the development and survival of its host. However, we did not confirm elimination of Wolbachia with PCR upon antibiotic treatment, nor did we check whether other bacteria were affected as well. Similar results have been found in the leafhopper species Empoasca fabae Harris, 1841, and Nephotettix cincticeps (Uhler, 1896) (Hemiptera: Cicadellidae). In these species, nymph mortality was higher after bacteria were removed with antibiotics (DeLay 2013). In Empoasca fabae, removal of the symbionts also affected their normal development and reproduction (DeLay 2013). Although Wolbachia is unlikely to induce parthenogenesis, Empoasca could still benefit from its infection. Wolbachia can positively influence host development by increasing their fitness (Weeks et al. 2007, Engelstädter and Hurst 2009, Jaenike 2012), fecundity (Stolk and Stouthamer 1996), or longevity (Dobson et al. 2004). Also, Rickettsia may have these effects on the general host fitness (Perlman et al. 2006).

In addition, occasional bacteria were detected in some Empoasca species, such as the gamma-proteobacteria of E. decedens and morphotype C. They seem closely related to bacteria found in other Hemiptera. Although it is unlikely that they manipulate the mode of reproduction of their host, they may be gut symbionts or secondary endosymbionts that affect host fitness. Also, the bacterium of E. alsiosa may not be a contaminant based on its close relationships with Lactococcus. It could be a transient bacterium or secondary symbiont as well.

In conclusion, Rickettsia may be responsible for the induction of parthenogenesis in Empoasca as they are associated with the unisexual morphotypes but are absent in the bisexual species. However, it may be difficult to prove this by treating the host with antibiotic, as Empoasca harbor additional bacteria that may be necessary for their survival. They are also polyploids, so it is not possible to know if polyploidy or bacteria are responsible for thelytokous reproduction in these leafhoppers. We found also that Asaia bacteria are omnipresent in all Empoasca of Madeira and postulate that Asaia is a nutritional symbiont of Empoasca leafhoppers. The bacterial diversity in Empoasca, including intracellular bacteria, omnipresent bacteria, and less frequent bacteria, makes it an interesting system for studying host-bacteria interactions and determining the ecological drivers of the costs and benefits of these associations.

\section{Acknowledgments}

We thank Valentina Kuznetsova for critical review of the paper and useful comments on the manuscript. We also thank the reviewers for valuable comments. This study was supported by the Fundação para a Ciência e a Tecnologia (FCT) research project Origin of multiple parthenoforms of Empoasca leafhoppers in Madeira Island (PTDC/BIA-BEC/103411/2008). We gratefully acknowledge Nelio Freitas for providing the photos of Empoasca.

\section{References List}

Adachi-Hagimori, T., K. Miura, and R. Stouthamer. 2008. A new cytogenetic mechanism for bacterial endosymbiont-induced parthenogenesis in Hymenoptera. Proc. Biol. Sci. 275: 2667-2673.

Aguin-Pombo, D., and C. Freitas. 2008. An annotated checklist of the Cicadomorpha and Fulgoromorpha (Hemiptera) of the Madeira and Salvages archipelagos. Zootaxa 1762: 1-28.

Aguin-Pombo, D., and N. Freitas. 2020. Empoasca fabalis (Hemiptera: Cicadellidae): first report of an invasive pest of sweet potatoes in Portugal (Madeira Island). Zootaxa 4838: zootaxa.4838.1.9.

Aguin-Pombo, D., V. Kuznetsova, and N. Freitas. 2006. Multiple parthenoforms of Empoasca leafhoppers from Madeira Island: where are these unisexual forms coming from? J. Hered. 97: 171-176. 
Akingbohungbe, A. E. 1983. Nomenclatural problems, biology, host plant and possible vector status of Auchenorrhyncha associated with crop plants in Nigeria, pp. 365-370. In W. J. Knight, N. C. Pant, T. S. Robertson, and M. R. Wilson (eds.), Proceedings of the 1st International workshop on leafhoppers and planthoppers of economic importance. CAB International Institute of Entomology, London, United Kingdom.

Baumann, P. 2005. Biology bacteriocyte-associated endosymbionts of plant sap-sucking insects. Annu. Rev. Microbiol. 59: 155-189.

Bigliardi, E., L. Sacchi, M. Genchi, A. Alma, M. Pajoro, D. Daffonchio, M. Marzorati, and A. M. Avanzati. 2006. Ultrastructure of a novel Cardinium sp. symbiont in Scaphoideus titanus (Hemiptera: Cicadellidae). Tissue Cell 38: 257-261.

Bing, X. L., D. S. Zhao, and X. Y. Hong. 2019. Bacterial reproductive manipulators in rice planthoppers. Arch. Insect Biochem. Physiol. 101: e21548.

Bressan, A. 2014. Emergence and evolution of Arsenophonus bacteria as insect-vectored plant pathogens. Infect. Genet. Evol. 22: 81-90.

Chen, S. J., F. Lu, J. A. Cheng, M. X. Jiang, and M. O. Way. 2012. Identification and biological role of the endosymbionts Wolbachia in rice water weevil (Coleoptera: Curculionidae). Environ. Entomol. 41: 469-477.

Chouaia, B., P. Rossi, S. Epis, M. Mosca, I. Ricci, C. Damiani, U. Ulissi, E. Crotti, D. Daffonchio, C. Bandi, et al. 2012. Delayed larval development in Anopheles mosquitoes deprived of Asaia bacterial symbionts. BMC Microbiol. 12(Suppl. 1): S2.

Crotti, E., A. Rizzi, B. Chouaia, I. Ricci, G. Favia, A. Alma, L. Sacchi, K. Bourtzis, M. Mandrioli, A. Cherif, et al. 2010. Acetic acid bacteria, newly emerging symbionts of insects. Appl. Environ. Microbiol. 76: 6963-6970.

Davis, M. J., Z. Ying, B. R. Brunner, A. Pantoja, and F. H. Ferwerda. 1998. Rickettsial relative associated with papaya bunchy top disease. Curr. Microbiol. 36: 80-84.

DeLay, B. D. 2013. Symbionts associated with the salivary glands of the potato leafhopper, Empoasca fabae, and their function when feeding on leguminous hosts. PhD dissertation, University of Pennsylvania, Philadelphia, PA.

Dobson, S. L., and W. Rattanadechakul. 2001. A novel technique for removing Wolbachia infections from Aedes albopictus (Diptera: Culicidae). J. Med. Entomol. 38: 844-849.

Dobson, S. L., W. Rattanadechakul, and E. J. Marsland. 2004. Fitness advantage and cytoplasmic incompatibility in Wolbachia single- and superinfected Aedes albopictus. Heredity (Edinb) 93: 135-142.

Downie, D. A., and P. J. Gullan. 2005. Phylogenetic congruence of mealybugs and their primary endosymbionts. J. Evol. Biol. 18: 315-324.

Duron, O., D. Bouchon, S. Boutin, L. Bellamy, L. Zhou, J. Engelstädter, and G. D. Hurst. 2008. The diversity of reproductive parasites among arthropods: Wolbachia do not walk alone. BMC Biol. 6: 27.

Elias-Costa, A. J., V. A. Confalonieri, A. A. Lanteri, and M. S. Rodriguero. 2019. Game of clones: is Wolbachia inducing speciation in a weevil with a mixed reproductive mode? Mol. Phylogenet. Evol. 133: 42-53.

Engelstädter, J., and G. D. D. Hurst. 2009. The ecology and evolution of microbes that manipulate host reproduction. Annu. Rev. Ecol. Evol. Syst. 40: 127-149.

Favia, G., I. Ricci, C. Damiani, N. Raddadi, E. Crotti, M. Marzorati, A. Rizzi, R. Urso, L. Brusetti, S. Borin, et al. 2007. Bacteria of the genus Asaia stably associate with Anopheles stephensi, an Asian malarial mosquito vector. Proc. Natl. Acad. Sci. USA 104: 9047-9051.

Feng, S., Q. Yang, H. Li, F. Song, V. Stejskal, G. P. Opit, W. Cai, Z. Li, and R. Shao. 2018. The highly divergent mitochondrial genomes indicate that the booklouse, Liposcelis bostrychophila (Psocoptera: Liposcelididae) is a cryptic species. G3 (Bethesda) 8: 1039-1047.

Folmer, O., M. Black, W. Hoeh, R. Lutz, and R. Vrijenhoek 1994. DNA primers for amplification of mitochondrial cytochrome c oxidase subunit I from diverse metazoan invertebrates. Mol. Mar. Biol. Biotechnol. 3:294-297.

Frati, F., I. Negri, P. P. Fanciulli, M. Pellecchia, V. De Paola, V. Scali, and R. Dallai. 2004. High levels of genetic differentiation between Wolbachiainfected and non-infected populations of Folsomia candida (Collembola, Isotomidae). Pedobiologia 48: 461-468.

Freitas, N., and D. Aguin-Pombo. 2005. Distribution, food plants and control of Asymmetrasca decedens (Paoli, 1932) (Hemiptera: Cicadellidae). Bol. Mus. Mun. Funchal 56: 23-39.
Gherna, R. L., J. H., Werren, W. Weisburg, R., Cote, C. R. Woese, L. Mandelco, and D. J. Brenner. 1991. Arsenophonus nasoniae gen. nov., sp. nov., the causative agent of the son-killer trait in the parasitic wasp Nasonia vitripennis. Int. J. Syst. Evol. Microbiol. 41: 563-565.

Giorgini, M., U. Bernardo, M. M. Monti, A. G. Nappo, and M. Gebiola. 2010. Rickettsia symbionts cause parthenogenetic reproduction in the parasitoid wasp Pnigalio soemius (Hymenoptera: Eulophidae). Appl. Environ. Microbiol. 76: 2589-2599.

Gokhman, V., and V. Kuznetsova. 2017. Parthenogenesis in Hexapoda: holometabolous insects. J. Zool. Syst. Evol. Res. 56: 23-34.

Gonella, E., I. Negri, M. Marzorati, M. Mandrioli, L. Sacchi, M. Pajoro, E. Crotti, A. Rizzi, E. Clementi, R. Tedeschi, et al. 2011. Bacterial endosymbiont localization in Hyalesthes obsoletus, the insect vector of Bois noir in Vitis vinifera. Appl. Environ. Microbiol. 77: 1423-1435.

Gonella, E., E. Crotti, A. Rizzi, M. Mandrioli, G. Favia, D. Daffonchio, and A. Alma. 2012. Horizontal transmission of the symbiotic bacterium Asaia sp. in the leafhopper Scaphoideus titanus Ball (Hemiptera: Cicadellidae). BMC Microbiol. 12(Suppl. 1): S4.

Gonella, E., E. Crotti, M. Mandrioli, D. Daffonchio, and A. Alma. 2018. Asaia symbionts interfere with infection by Flavescence dorée phytoplasma in leafhoppers. J. Pest Sci. 91: 1033-1046.

Gonella, E., R. Tedeschi, E. Crotti, and A. Alma. 2019. Multiple guests in a single host: interactions across symbiotic and phytopathogenic bacteria in phloem-feeding vectors - a review. Entomol. Exp. Appl. 167: 171-185.

Henke, C., H. Nickel, S. Scheu, and I. Schaefer. 2013. Evidence for Wolbachia in leafhoppers of the genus Eupteryx with intersexual morphotypes. Bull. Insectol. 66: 109-118.

Hilgenboecker, K., P. Hammerstein, P. Schlattmann, A. Telschow, and J. H. Werren. 2008. How many species are infected with Wolbachia? A statistical analysis of current data: Wolbachia infection rates. FEMS Microbiol. Lett. 281: 215-220.

Himler, A. G., T. Adachi-Hagimori, J. E. Bergen, A. Kozuch, S. E. Kelly, B. E. Tabashnik, E. Chiel, V. E. Duckworth, T. J. Dennehy, E. Zchori-Fein, et al. 2011. Rapid spread of a bacterial symbiont in an invasive whitefly is driven by fitness benefits and female bias. Science 332: 254-256.

Hoshizaki, S., and T. Shimada. 1995. PCR-based detection of Wolbachia, cytoplasmic incompatibility microorganisms, infected in natural populations of Laodelphax striatellus (Homoptera: Delphacidae) in central Japan: has the distribution of Wolbachia spread recently? Insect Mol. Biol. 4: 237-243.

Huigens, M. E., and R. Stouthamer. 2003. Parthenogenesis associated with Wolbachia, pp. 247-265. In K. Bourtzis and T. A. Miller (eds.), Insect Symbiosis. CRC Press, Boca Raton, FL.

Hurst, G. D., and F. M. Jiggins. 2000. Male-killing bacteria in insects: mechanisms, incidence, and implications. Emerg. Infect. Dis. 6: 329-336.

Hurst, G. D. D., F. M. Jiggins, J. H. G. von der Schulenburg, D. Bertrand, S. A. West, I. I. Goriacheva, I. A. Zakharov, J. H. Werren, R. Stouthamer, and M. E. N. Majerus. 1999. Male-killing Wolbachia in two species of insect. Proc. R. Soc. Lond. B Biol. Sci. 266: 735-740.

Iasur-Kruh, L., V. Naor, T. Zahavi, M. J. Ballinger, R. Sharon, W. E. Robinson, S. J. Perlman, and E. Zchori-Fein. 2017. Bacterial associates of Hyalesthes obsoletus (Hemiptera: Cixiidae), the insect vector of bois noir disease, with a focus on cultivable bacteria. Res. Microbiol. 168: 94-101.

Ishii, Y., Y. Matsuura, S. Kakizawa, N. Nikoh, and T. Fukatsu. 2013. Diversity of bacterial endosymbionts associated with Macrosteles leafhoppers vectoring phytopathogenic phytoplasmas. Appl. Environ. Microbiol. 79: 5013-5022.

Jaenike, J. 2012. Population genetics of beneficial heritable symbionts. Trends Ecol. Evol. 27: 226-232.

Kageyama, D., S. Narita, and M. Watanabe. 2012. Insect sex determination manipulated by their endosymbionts: incidences, mechanisms and implications. Insects 3: 161-199.

Kobiałka, M., A. Michalik, M. Walczak, Ł. Junkiert, and T. Szklarzewicz. 2016. Sulcia symbiont of the leafhopper Macrosteles laevis (Ribaut, 1927) (Insecta, Hemiptera, Cicadellidae: Deltocephalinae) harbors Arsenophonus bacteria. Protoplasma 253: 903-912. 
Kobiałka, M., A. Michalik, J. Szwedo, and T. Szklarzewicz. 2018a. Diversity of symbiotic microbiota in Deltocephalinae leafhoppers (Insecta, Hemiptera, Cicadellidae). Arthropod Struct. Dev. 47: 268-278.

Kobiałka, M., A. Michalik, and T. Szklarzewicz. 2018b. An unusual symbiotic system in Elymana kozhevnikovi (Zachvatkin, 1938) and Elymana sulphurella (Zetterstedt, 1828) (Insecta, Hemiptera, Cicadellidae: Deltocephalinae). Folia Biol. 66: 13-24.

Koivisto, R. K. K., and H. R. Braig. 2003. Microorganisms and parthenogenesis. Biol. J. Linn. Soc. Lond. 79: 43-58.

Kumar, S., G. Stecher, M. Li, C. Knyaz, and K. Tamura. 2018. MEGA X: molecular evolutionary genetics analysis across computing platforms. Mol. Biol. Evol. 35: 1547-1549.

Kuznetsova, V., and D. Aguin-Pombo. 2015. Comparative cytogenetics of Auchenorrhyncha (Hemiptera, Homoptera): a review. Genet. Cytogenet. Insects ZooKeys 538: 63-93.

Lachowska, D., L. Kajtoch, and S. Knutelski. 2010. Occurrence of Wolbachia in central European weevils: correlations with host systematics, ecology, and biology. Entomol. Exp. Appl. 135: 105-118.

Lane, D. J. 1991. 16S/23S rRNA sequencing, pp. 115-175. In E. Stackebrandt and M. Goodfellow (eds.), Nucleic acid techniques in bacterial systematics. John Wiley and Sons, New York, NY.

Lawson, E. T., T. A. Mousseau, R. Klaper, M. D. Hunter, and J. H. Werren. 2001. Rickettsia associated with male-killing in a buprestid beetle. Heredity (Edinb) 86: 497-505.

Li, Y. Y., K. D. Floate, P. G. Fields, and B.-P. Pang. 2014. Review of treatment methods to remove Wolbachia bacteria from arthropods. Symbiosis 62: $1-15$.

Li, S., C. Zhou, G. Chen, and Y. Zhou. 2017. Bacterial microbiota in small brown planthopper populations with different rice viruses. J. Basic Microbiol. 57: 590-596.

Li, Y., X. Liu, and H. Guo. 2018. Variations in endosymbiont infection between buprofezin-resistant and susceptible strains of Laodelphax striatellus (Fallén). Curr. Microbiol. 75: 709-715.

Li, F., P. Li, H. Hua, M. Hou, and F. Wang. 2020. Diversity, tissue localization, and infection pattern of bacterial symbionts of the white-backed planthopper, Sogatella furcifera (Hemiptera: Delphacidae). Microb. Ecol. 79: 720-730.

Lian, Q. X., J.-F. Liu, M.-F. Yang, and C. Han, 2016. Molecular identification and detection of Rickettsia endosymbiont in the green leafhopper: Cicadella viridis (Hemiptera: Cicadellidae). J. Asia Pac. Entomol. 19: 659-664.

Ma, W. J., F. Vavre, and L. W. Beukeboom. 2014. Manipulation of arthropod sex determination by endosymbionts: diversity and molecular mechanisms. Sex Dev. 8: 59-73.

Ma, W. J., B. A. Pannebakker, L. van de Zande, T. Schwander, B. Wertheim, and L. W. Beukeboom. 2015. Diploid males support a two-step mechanism of endosymbiont-induced thelytoky in a parasitoid wasp. BMC Evol. Biol. 15: 84.

Mazur, M. A., M. Holecová, D. Lachowska-Cierlik, A. Lis, D. Kubisz, and Ł. Kajtoch. 2016. Selective sweep of Wolbachia and parthenogenetic host genomes - the example of the weevil Eusomus ovulum. Insect Mol. Biol. 25: 701-711.

Michalik, A., W. Jankowska, and T. Szklarzewicz. 2009. Ultrastructure and transovarial transmission of endosymbiotic microorganisms in Conomelus anceps and Metcalfa pruinosa (Insecta, Hemiptera, Fulgoromorpha). Folia Biol. (Krakow) 57: 131-137.

Michalik, A., J. Szwedo, A. Stroiński, D. Świerczewski, and T. Szklarzewicz. 2018. Symbiotic cornucopia of the monophagous planthopper Ommatidiotus dissimilis (Fallén, 1806) (Hemiptera: Fulgoromorpha: Caliscelidae). Protoplasma 255: 1317-1329.

Mitraka, E., S. Stathopoulos, I. Siden-Kiamos, G. K. Christophides, and C. Louis. 2013. Asaia accelerates larval development of Anopheles gambiae. Pathog. Glob. Health 107: 305-311.

Moran, N. A., J. P. McCutcheon, and A. Nakabachi. 2008. Genomics and evolution of heritable bacterial symbionts. Annu. Rev. Genet. 42: 165-90. doi:10.1146/annurev.genet.41.110306.130119
Moya, A., J. Peretó, R. Gil, and A. Latorre. 2008. Learning how to live together: genomic insights into prokaryote-animal symbioses. Nature Ver. Genet. 9: 218-229.

Nakamura, Y., F. Yukuhiro, M. Matsumura, and H. Noda. 2012. Cytoplasmic incompatibility involving Cardinium and Wolbachia in the white-backed planthopper Sogatella furcifera (Hemiptera: Delphacidae). Appl. Entomol. Zool. 47: 273-283.

Nast, J. 1972. Palaearctic Auchenorrhyncha (Homoptera) an annotated check list. Polish Scientific Publications, Warszawa, Poland.

Nast, J. 1987. The Auchenorrhyncha (Homoptera) of Europe. Ann. Zool. Fenn. 40: 535-661.

Negri, I., M. Pellecchia, P. J. Mazzoglio, A. Patetta, and A. Alma. 2006. Feminizing Wolbachia in Zyginidia pullula (Insecta, Hemiptera), a leafhopper with an XX/X0 sex-determination system. Proc. Biol. Sci. 273: 2409-2416.

Noda, H. 1977. Histological and histochemical observation of intracellular yeastlike symbiotes in the fat body of the smaller brown planthopper, Laodelphax striatellus (Homoptera: Delphacidae). Appl. Entomol. Zool. 12: 134-141.

Noda, H. 1984. Cytoplasmic incompatibility in a rice planthopper. J. Hered. 75: 345-348.

Noda, H., Y. Koizumi, Q. Zhang, and K. Deng. 2001. Infection density of Wolbachia and incompatibility level in two planthopper species, Laodelphax striatellus and Sogatella furcifera. Insect Biochem. Mol. Biol. 31: 727-737.

Noda, H., K. Watanabe, S. Kawai, F. Yukuhiro, T. Miyoshi, M. Tomizawa, Y. Koizumi, N. Nikoh, and T. Fukatsu. 2012. Bacteriome-associated endosymbionts of the green rice leafhopper Nephotettix cincticeps (Hemiptera: Cicadellidae). Appl. Entomol. Zool. 47: 217-225.

Perlman, S. J., M. S. Hunter, and E. Zchori-Fein. 2006. The emerging diversity of Rickettsia. Proc. Biol. Sci. 273: 2097-2106.

Perlman, S. J., C. N. Hodson, P. T. Hamilton, G. P. Opit, and B. E. Gowen. 2015. Maternal transmission, sex ratio distortion, and mitochondria. Proc. Natl. Acad. Sci. USA 112: 10162-10168.

Perotti, M. A., H. K. Clarke, B. D. Turner, H. R. Braig, M. A. Perotti, H. K. Clarke, B. D. Turner, and H. R. Braig. 2006. Rickettsia as obligate and mycetomic. FASEB J. 20: 2372-2374.

Pike, N., and R. Kingcombe. 2009. Antibiotic treatment leads to the elimination of Wolbachia endosymbionts and sterility in the diplodiploid collembolan Folsomia candida. BMC Biol. 7: 54 .

Posada, D. 2008. jModelTest: phylogenetic model averaging. Mol. Biol. Evol. 25: 1253-1256

Prakash, B. M., and H. P. Puttaraju. 2007. Frequency of infection with A and B supergroup Wolbachia in insects and pests associated with mulberry and silkworm. J. Biosci. 32: 671-676.

Qu, L. Y., Y.-H. Lou, H.-W. Fan, Y.-X. Ye, H.-J. Huang, M.-Q. Hu, Y.-N. Zhu, and C.-X. Zhang. 2013. Two endosymbiotic bacteria, Wolbachia and Arsenophonus, in the brown planthopper Nilaparvata lugens. Symbiosis 61: 47-53.

Rodriguero, M. S., V. A. Confalonieri, J. V. C. Guedes, and A. A. Lanteri. 2010. Wolbachia infection in the tribe Naupactini (Coleoptera, Curculionidae): association between thelytokous parthenogenesis and infection status: Wolbachia infection in the tribe Naupactini. Insect. Mol. Biol. 19: 631-640.

Roh, S. W., Y.-D. Nam, H.-W. Chang, K.-H. Kim, M.-S. Kim, J.-H. Ryu, S.H. Kim, W.-J. Lee, and J.-W. Bae. 2008. Phylogenetic characterization of two novel commensal bacteria related to innate immune homeostasis in Drosophila. J. Appl. Environ. Microbiol. 74: 6171-6177.

Sacchi, L., M. Genchi, E. Clementi, E. Bigliardi, A. M. Avanzati, M. Pajoro, I. Negri, M. Marzorati, E. Gonella, A. Alma, et al. 2008. Multiple symbiosis in the leafhopper Scaphoideus titanus (Hemiptera: Cicadellidae): details of transovarial transmission of Cardinium sp. and yeast-like endosymbionts. Tissue Cell 40: 231-242.

Saglio, P., M. Lhospital, D. Lafleche, G. Dupont, J. M. Bové, J. G. Tully, and E. A. Freundt. 1973. Spiroplasma citri gen. and sp. n.: a mycoplasma-like organism associated with "stubborn" disease of citrus. Int. J. Syst. Evol. Microbiol. 23: 191-204. 
Schulenburg, J. H. G. V., M. von der Habig, J. J. Sloggett, K. M. Webberley, D. Bertrand, G. D. D. Hurst, and M. E. Majerus. 2001. Incidence of male-killing Rickettsia spp. (alpha-proteobacteria) in the ten-spot ladybird beetle Adalia decempunctata L. (Coleoptera: Coccinellidae). Appl. Environ. Microbiol. 67: 270-277.

Son, Y., S. Luckhart, X. Zhang, M. J. Lieber, and E. E. Lewis. 2008. Effects and implications of antibiotic treatment on Wolbachia-infected vine weevil (Coleoptera: Curculionidae). Agric. For. Entomol. 10: 147-155.

Stolk, C., and R. Stouthamer. 1996. Influence of a cytoplasmic incompatibility inducing Wolbachia on the fitness of the parasitoid wasp Nasonia vitripennis. Proc. Sec. Exp. Appl. Entomol. Neth. Entomol. Soc. 7: 33-38.

Stouthamer, R. 1997. Wolbachia-induced parthenogenesis, pp. 102-124. In O. Scott, A. A. Hoffmann, and J. H. Werren (eds.), Influential passengers. Inherited microorganisms and arthropod reproduction. Oxford University Press, Oxford, United Kingdom.

Stouthamer, R., and D. J. Kazmer, 1994. Cytogenetics of microbe-associated parthenogenesis and its consequences for gene flow in Trichogramma wasps. Heredity 73: 317-327.

Stouthamer, R., and F. Mak. 2002. Influence of antibiotics on the offspring production of the Wolbachia-infected parthenogenetic parasitoid Encarsia formosa. J. Invert. Path. 80: 41-45.

Stouthamer, R., J. A. Breeuwer, and G. D. Hurst. 1999. Wolbachia pipientis: microbial manipulator of arthropod reproduction. Annu. Rev. Microbiol. 53: 71-102.

Suomalainen, E., A. Saura, and J. Lokki. 1987. Cytology and evolution in parthenogenesis. CRC Press.

Takiya, D. M., P. L. Tran, C. H. Dietrich, and N. A. Moran. 2006. Co-cladogenesis spanning three phyla: leafhoppers (Insecta: Hemiptera: Cicadellidae) and their dual bacterial symbionts: codiversification of sharpshooter endosymbionts. Mol. Ecol. 15: 4175-4191.

Thao, M. L., N. A. Moran, P. Abbot, E. B. Brennan, D. H. Burckhardt, and P. Baumann. 2000. Cospeciation of psyllids and their primary prokaryotic endosymbionts. Appl. Environ. Microbiol. 66: 2898-2905.

Timmermans, M. J. T. N., and J. Ellers. 2009. Wolbachia endosymbiont is essential for egg hatching in a parthenogenetic arthropod. Evol. Ecol. 23: 931-942. van der Kooi, C. J., C. Matthey-Doret, and T. Schwander. 2017. Evolution and comparative ecology of parthenogenesis in haplodiploid arthropods. Evol. Lett. 1: 304-316.

Weeks, A. R., F. Marec, and J. A. Breeuwer. 2001. A mite species that consists entirely of haploid females. Science 292: 2479-2482.

Weeks, A. R., M. Turelli, W. R. Harcombe, K. T. Reynolds, and A. A. Hoffmann. 2007. From parasite to mutualist: rapid evolution of Wolbachia in natural populations of Drosophila. PLoS Biol. 5: e114.

Weinert, L. A., J. H. Werren, A. Aebi, G. N. Stone, and F. M. Jiggins. 2009. Evolution and diversity of Rickettsia bacteria. BMC Biol. 7: 6 .

Werren, J. H., and D. M. Windsor. 2000. Wolbachia infection frequencies in insects: evidence of a global equilibrium? Proc. Biol. Sci. 267: 1277-1285.

Werren, J. H., G. D. Hurst, W. Zhang, J. A. Breeuwer, R. Stouthamer, and M. E. Majerus. 1994. Rickettsial relative associated with male killing in the ladybird beetle (Adalia bipunctata). J. Bacteriol. 176: 388-394.

Werren, J. H., L. Baldo, and M. E. Clark. 2008. Wolbachia: master manipulators of invertebrate biology. Nat. Rev. Microbiol. 6: 741-751.

Yusuf, M., and B. Turner. 2004. Characterization of Wolbachia-like bacteria isolated from the parthenogenetic stored-product pest psocid Liposcelis bostrychophila (Badonnel) (Psocoptera). J. Stor. Prod. Res. 40: 207-225.

Zchori-Fein, E. I. N. A. T., and S. J. Perlman. 2004. Distribution of the bacterial symbiont Cardinium in arthropods. Mol. Ecol. 13: 2009-2016.

Zhang, X.-F., D.-X. Zhao, and X.-Y. Hong. 2012. Cardinium - the leading factor of cytoplasmic incompatibility in the planthopper Sogatella furcifera doubly infected with Wolbachia and Cardinium. Environ. Entomol. 41: 833-840.

Zhang, K. J., X. Han, and X. Y. Hong. 2013. Various infection status and molecular evidence for horizontal transmission and recombination of Wolbachia and Cardinium among rice planthoppers and related species. Insect Sci. 20: 329-344.

Zhang, J. H., N. Yu, X. X. Xu, and Z. W. Liu. 2019. Community structure, dispersal ability and functional profiling of microbiome existing in fat body and ovary of the brown planthopper, Nilaparvata lugens. Insect Sci. 26: 683-694.

Zhang, X., T. P. Li, C. Y. Zhou, D. S. Zhao, Y. X. Zhu, X. L. Bing, H. J. Huang, and X. Y. Hong. 2020. Antibiotic exposure perturbs the bacterial community in the small brown planthopper Laodelphax striatellus. Insect Sci. 27: 895-907. 